\title{
Pattern of Drug Abuse among Street Children of Dhaka: Inhalants are the Most Popular Drug
}

\author{
Jakir Hossain Bhuiyan Masud ${ }^{1}$, Md. Moniruzzaman Khan², Jesmin ${ }^{3}$
}

\begin{abstract}
Background: Number of street children has been rising in Dhaka, the capital of Bangladesh, in recent years and also the prevalence of substance abuse is increasing among these children. Objective: This research work focuses on understanding street children's perception/attitudes towards substance abuse. Materials and method: For this study, an inquiry based, self-administrated questionnaire was generated and a survey was conducted by authorized, trained persons. A total of 80 participants were enrolled in this initial research work. Results: Studying respondents from two major areas of Dhaka, it came out that sniffing dendrite is the most popular adhesive/inhalant among children because of its easy availability. For these children, the initiation process of sniffing adhesives starts as a part of street culture introduced by peers $187.5 \%, n=$ 70), for getting accepted into social street gangs. Thus, these children started drug abuse as a mean of endurance along with a little pleasurelescapism, even for a while to survive within the harsh reality of street life. Data from this initial study were used to build a topological-model of present/oncoming consequences/threats of substance abuse with suggested routes of social/medical interventions. The most encouraging fact is that understanding the adverse consequences of drug abuse, most of these children wanted to quit drug abuse $(70 \%, n=56)$ and wished for a better life. Conclusion: It is believed that this model would help in implementing measures for systematic drug abuse cessation for long-term rehabilitation programmes for these children, ensuring every child's right to have a secured, healthy life.
\end{abstract}

Keywords: Drug abuse; sniffing inhalants; dendrite; street children.

Delta Med Col J. Jan 2018;6(1):29 - 34

\section{Introduction}

Tens of millions of children around the world find themselves living or working in the streets. ${ }^{1}$ There are over 600,000 street children in Bangladesh, about $50 \%$ of them are between ages of 11-19 years, and more than a third of them are settled in

Dhaka $^{2}$ and this number is further going to be increased at an alarming rate by the year 2024 (Fig 1). The major reasons for increasing numbers of children to be on the streets are poverty, broken family, natural disasters and growing urbanization..$^{1,2}$

1. Ex. Research Associate, National Heart Foundation Hospital \& Research Institute, Mirpur, Dhaka, Bangladesh.

2. Assistant Professor, Hamdard University of Bangladesh.

3. Professor, Dept. of Genetic Engineering \& Biotechnology, University of Dhaka, Bangladesh.

Correspondence: Jakir Hossain Bhuiyan Masud. e-mail: jakir_msd@yahoo.com 


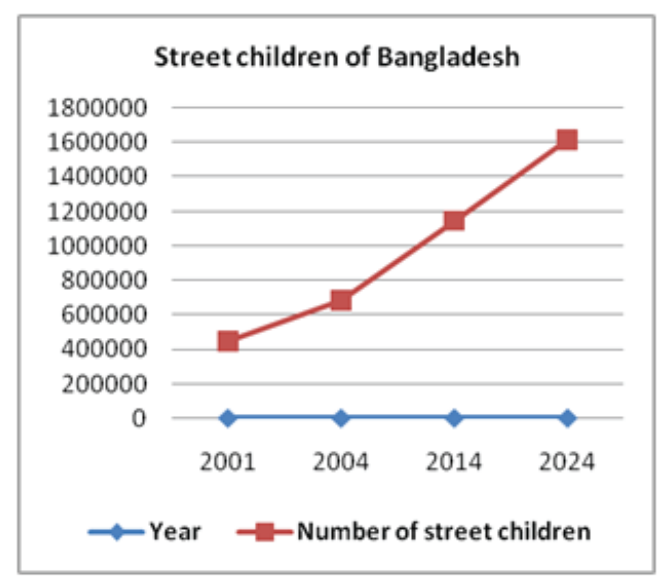

Fig 1: Number of street children every year

Drug abuse is common among street children all over the world as it is in Bangladesh. Like many of the low and middle income countries around the globe, also in Bangladesh, the most popular drug among street children are the inhalants, like gum/glue, acetone, gasoline, and paint thinner. ${ }^{3,4}$ Street children are likely to gravitate toward inhalants as they are cheap, legal, and easy to access. Although, in other parts of the world sniffing adhesive/gums has been prevailing for the last forty years, however, in Bangladesh it has been introduced only very recently. ${ }^{3,4}$ So, it is very important at this stage, to investigate thoroughly the cause/consequences of substance abuse among street children to better combat and commence strategies for preventing any further damage.

\section{Materials and method}

This cross sectional study was conducted from June 2013-May 2014. An inquiry based, self-administrated questionnaire was generated (supplemental file) and a survey was conducted by authorized, trained persons. This initial study, collected data from two major areas of Dhaka city of Bangladesh which have a high prevalence of the targeted group. One is around Dhaka University premises (Ramna Thana, Dhaka Medical College
Hospital) and the other around Mirpur Thana (Mirpur-1, Gabtali). The respondent group of the street children and youth selected for this study were aged between 12 to $18(\leq 18)$ years who spent the majority of their time roaming \&/or working on the street and not enrolled in any educational institution at that time, had limited or no contact with their family and spent both days and nights living and sleeping on the streets. A total of 80 participants were enrolled in this initial research work.

This study was reviewed and approved by the Institutional Review Boards and Research, Ethical Committee of Hakim Said Eastern Medical College, Dhaka, Bangladesh. For this study a waiver of individual guardian consent as per human subjects' regulations for minors, was also been provided as the subjects of this study are street children who have no families, so individuals' guardian consent couldn't be possible and without which practically this study could not be carried out. Moreover, the street gang leaders were avoided to obtain the real scenario as they are more manipulating and controlling over the children. Thus, this research work was carried out in an informal and friendly way. Participants were approached individually; all respondents were informed about the purpose of this study. Individual's verbal consent and assent, assuring their willingness to participate were obtained before the interview. All information was kept anonymous, confidential and used for research purpose only. A survey was conducted by social workers trained in working with children. This study recruits both boys and girls on the street to capture the diverse perspectives.

A questionnaire was developed to collect data through face-to-face interviews with the respondents. Data entry and cleaning was done under the supervision of the researchers. Data analysis was done by SPSS version 16.0. Frequencies and percentage were calculated for selected variables in relation to qualitative themes that emerged in order to describe substance use. 


\section{Results}

This was an initial study focusing to understand street children's perceptions and attitudes towards drug and substance abuse. The socio-demographic characteristics of the street dwellers are shown in Table I. Data generated through this study indicated that street children of Dhaka city, mostly sniff adhesive inhalants like gum, locally known as dandy (dendrite) along with smoking. The widespread availability, affordability, and legal status of glue make it the drug of choice for many street children. The drug abuse process is interesting, generally a little bit of the dendrite is taken inside a polythene bag and the pungent fume/odour of the adhesive is sniffed or inhaled by putting the mouth inside the bag. Groups of street children are usually seen huddled together, blowing into seemingly empty polythene bags in turns at several spots of Dhaka city. ${ }^{3,4}$ Some of them, especially those who were a bit old (above 15) also use Phensedyl, Pethidine, Ganja (cannabis) (Fig 2, Table I).

Table I: Distribution of the respondents by socio-demographic characteristics and types of addiction $(\mathrm{N}=\mathbf{8 0})$

\begin{tabular}{lcc}
\hline Variables & Frequency & Percentage (\%) \\
\hline Age & 46 & \\
$\leq 16$ & 34 & 57.5 \\
$>16$ & & 42.5 \\
Gender & 61 & 76.2 \\
$\quad$ Male & 19 & 23.8 \\
$\quad$ Female & & \\
Education & 72 & 90.0 \\
$\quad$ No formal education & 8 & 10.0 \\
$\quad$ Primary & & \\
Income (BDT) & 74 & 92.5 \\
$\quad \leq 200$ & 6 & 7.5 \\
$\quad>200$ & & \\
Daily Expenditure (BDT) & 76 & 95.0 \\
$\quad \leq 200$ & 4 & 5.0 \\
$\quad>200$ & & \\
Types of addiction & 27 & 33.8 \\
Smoking & 25 & 31.2 \\
Dandy/Gum/Glue/Dendrite & 20 & 25.0 \\
Pethidine & 6 & 7.5 \\
Phensedyl & 2 & 2.5 \\
Ganja &
\end{tabular}

Most of the respondents were in age group of $\leq 16$ years $(57.5 \%)$. Among the respondents $90 \%$ did not have any formal education and $92.5 \%$ had income level $\leq 200$ BDT. Among the respondents, most of them $33.8 \%$ used smoking and $31.2 \%$ used gum.

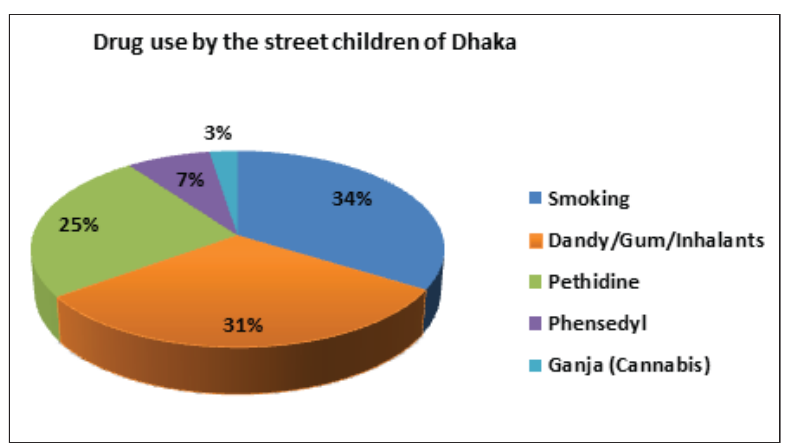

Fig 2: Drug use by street children of Dhaka

It was interesting to find out through data analysis of the respondents that the types of drug abuse within different age groups in a way correlate with their daily income and expenditures. Data generated through this study indicated that usually the younger children between 12-15 years of age have earnings less than $200 \mathrm{BDT} /$ day ( 2.6 USD), which they spent on buying foods (1-2 meals/day) and inhalants like gum/dandy $(32.5 \%, n=26)$. During the survey, these children reported that in the days when they couldn't earn much even not enough to buy food they generally spent that little earnings on buying drugs as it provided them pleasure, escapism even for a while, from the harsh reality of street life. The scenario for elder children (16-18 years) was a bit different. Their daily income is a little higher, between 200-500 BDT/day ( 2.6-6.5 USD). Analyzed data showed that these kids even tried hard to make some savings. They use it for buying foods (1-2 meals/day) and surely spent more on addiction like smoking, Phensedyl, Pethidine and Ganja $(43.8 \%, n=35)$ for a bit pleasure and escapism too (Table I).

It came out through interview with street children that peer influence and belonging play a major role in the initiation and prolonged drug use. The respondents of this survey who mostly use gum/dandy (dendrite) told that they chose to use dandy as their friends do $(87.5 \%, \mathrm{n}=70)$ and were first introduced to drugs by an elder within the group $(12.5 \%, \mathrm{n}=10)$ (Table II). Thus, the results of this study indicated that for the street children of Dhaka city essentially peer pressure and as a way to survive in the street were the most common 
reasons for starting drug abuse. It also came out that the widespread availability, affordability, and legal status of gum makes it the drug of choice for the street children. The majority of the children reported during the interview that they had started using drugs in order to cope with hunger, fear and being alone in the street and just continued from there on. Only a very few said that they were ended up using drugs out of inquisitiveness or experimentation.

Table II: Influence on street children for taking drugs

\begin{tabular}{lcc}
\hline $\begin{array}{l}\text { Influenced/introduced } \\
\text { taking drugs }\end{array}$ & Frequency (n) & Percentage (\%) \\
\hline Peer & 70 & 87.5 \\
Elder & 10 & 12.5 \\
Total & 80 & 100.0 \\
\hline
\end{tabular}

Most of the respondents in this study, both male and female, after knowing the adverse consequences of drug abuse expressed their strong desire and willingness to quit drugs $(70 \%, n=56)$. Not only that, all of the respondents wished for a better life (Table III).

Table III: Respondents desire to quit drug

\begin{tabular}{lccccc}
\hline \multirow{2}{*}{ Respondents } & \multicolumn{2}{c}{ Wanted to quit } & Total & $\chi^{2}$ & p-value \\
& Yes & Don't Know & & & \\
\hline Male & $46(75.4 \%)$ & $15(24.6 \%)$ & $61(100.0 \%)$ & & \\
Female & $10(52.6 \%)$ & $9(47.4 \%)$ & $19(100.0 \%)$ & 3.579 & 0.05 \\
Total & $56(70.0 \%)$ & $24(30.0 \%)$ & $80(100.0 \%)$ & & \\
\hline
\end{tabular}

\section{Discussion}

This is an initial study where only two major areas of Dhaka city were targeted and the data accumulated from respondents were analyzed. The objectives of this study were to identify the actual facts/reasons/factors that are driving street children to use drugs and also to understand their perceptions and attitudes towards substance use within the context of their experiences of life on the streets.
Often the first step in any types of drug abuse cessation has been, recognizing the problem and expressing a desire to quit. ${ }^{5-7}$ Most of the respondents in this study expressed their strong desire and willingness to quit drugs and all of the respondents wished for a better life. This is a very positive response as researches in other inhalant using populations have shown that having such strong motivation ${ }^{1,2}$ can only help the addicts to enter treatment with decreased chances of relapse. ${ }^{8,9}$ Although $30 \%$ of the street children, even don't know what to expect from life but this strong desire among the majority to quit drugs is a very positive response to consider and find out effective strategies for interventions and designing drug cessation programs for these street children, especially keeping in mind that most of these children entered into this dark world of addiction only for coping and survival. Children are the future of a nation; so their health, wellbeing should be put on priority.

Drug abuse is a major public health problem that impacts society on multiple levels. The scope of the problem is broad and requires innovative and multifaceted programmes for preventing, reducing and stopping substance use amongst children.

Street children especially who are drug abusers have much difficulty in re-entering society. 8,9 Once a child is addicted to something like gum/dandy (dendrite), it makes very difficult for them to go to school and have a normal family life. The adhesive dandy (dendrite) is a sweet-smelling intoxicating hydrocarbon with a complex structure which is a neurotoxin (Fig 3). It impairs brain's function and causes hallucination; affects mental health. It affects the cognitive abilities like to learn, adapt and to adjust. ${ }^{10}$ Not only that it has effects on red blood cells (RBC) and form aggregates (Fig 3), sometimes it also causes kidney or liver failure, paralysis and even sudden death from cardiac arrhythmia and other causes. ${ }^{3,4,11-13}$ Basically, dandy acts like a deadly intoxicating drug, directly or indirectly 
affecting the street children causing health threats on the current users and also having a greater risk of affecting those who would come in physical contact with them in future. ${ }^{12,13}$

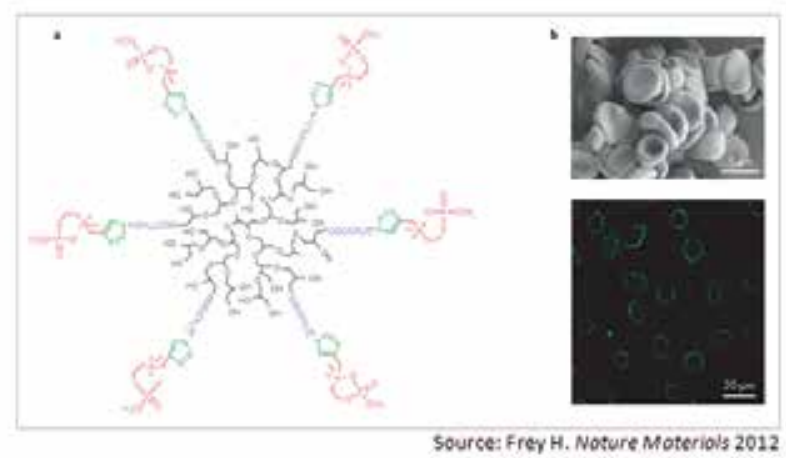

Fig 3: Complex structure of Dendrite (Dandy) which is a neurotoxin

There are complex factors that influence street children's substance addictions. Information gathered through this study; the cause, consequences of substance abuse among street children of Dhaka city were systematically analyzed and linked in order to relatedness and consequences like joining the pieces of a puzzle to capture the overall scenario and build a topological overview model. This model represents the present and incoming threats of substance abuse in turn, helped in identifying and suggesting routes, both medical/psychological and social based interventions (Fig 4).

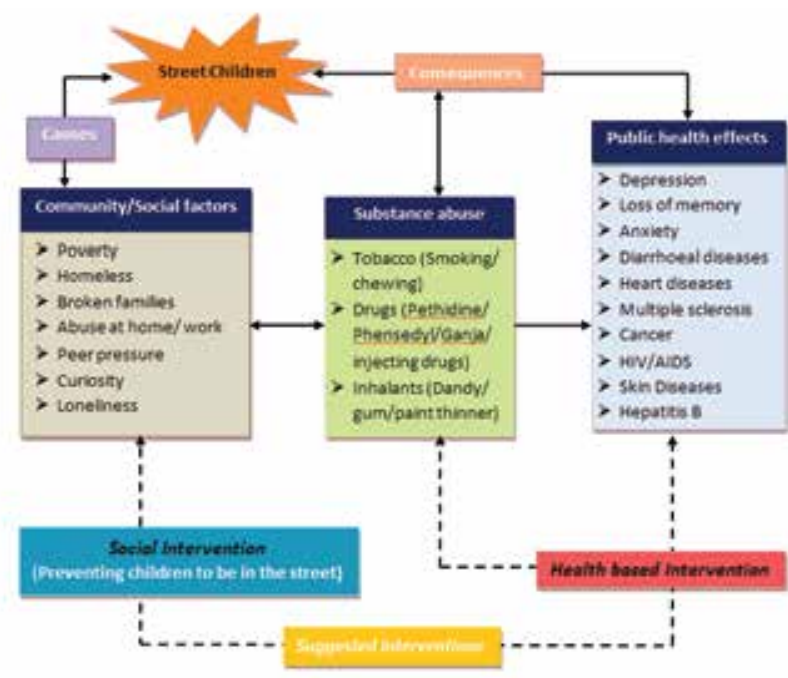

Fig 4: Cause and effect relation of addiction
To help and rehabilitate these children into any intervention, this study further suggests and emphasizes the need to integrate community, family and peers along with some traditional models of treatment. It is believed that at this level, gaining understanding through this model would help to better plan for cessation programmes and implementing measures to handle and save this vulnerable population. In future, further studies needed to be focused on gaining the perspectives of the community, policy makers and families of the street children to address and better implement these issues within the socioeconomic and cultural context of Dhaka.

Although, there is a 'National Child Act 2011' in Bangladesh ensuring every Childs' rights as an individual for food, shelter, better health and education ${ }^{14}$ but unfortunately most of these vulnerable street children even are not aware of their rights.

\section{Conclusion}

This study strongly recommended the need for community members, relevant stakeholders, researchers and policy makers to work together not only to mitigate substance abuse, but also to identify viable alternatives to street life ensuring every child's right to have a healthy and secure life. It is believed that the outcomes from this study would help to understand the current scenario of drug abuse by the street children of Dhaka city which in turn would help to better plan long term intervention strategies for preventing substance abuse and ensure every child's right to have a secure and healthy life.

\section{References}

1. unicef.org [Internet]. The State of the World's Children 2006: Excluded and Invisible. UNICEF. 2006 [cited 2016 Octo 30]. Available from: http://www.unicef.org/sowc06/pdfs/sowc06_fullrep ort.pdf. 
2. Islam KMN. Estimation of the Size and Projection of Street Children in Urban Areas of Bangladesh. Report prepared for the Ministry of Women and Children Affairs. 2005. Government of Bangladesh, BIDS: Dhaka.

3. Annual Drug Report of Bangladesh. Department of Narcotics Control, Ministry of Home Affairs, Government of the People's Republic of Bangladesh. 2013 [cited 2016 Octo 31]. Available from: http://www.dnc.gov.bd/report_dnc/annual_report_2 013.pdf.

4. Bilkis S. The Danger of Dendrite Use as a Drug. The Financial Express 20, 157. 10 Oct 2012.

5. Vederhus JK, Kristensen O. High Effectiveness of Self-Help Programs after Drug Addiction Therapy. BMC Psychiatry. 2006;6:35.

6. Huselid RF, Self EA, Gutierres SE. Predictors of Successful Completion of a Halfway-House Program for Chemically-Dependent Women. Am J Drug Alcohol Abuse. 1991;17:89-101.

7. Moos RH, King MJ. Participation in Community Residential Treatment and Substance Abuse Patients' Outcomes at Discharge. J Subst Abuse Treat. 1997; 14:71-80.

8. Coleman H, Charles G, Collins J. Inhalant Use by Canadian Aboriginal Youth. J Child Adolesc Subst Abuse. 2001;10(3):1-20.

9. Jumper-Thurman P, Plested B, Beauvais F. Treatment Strategies for Volatile Solvent Abusers in the United States. NIDA Res Monogr. 1995;148:250-59.

10. Dell CA. Youth Volatile Solvent Abuse Frequently Asked Questions. Canadian Centre for Substance Abuse. 2006 [cited 2016 Nov 6]. Available from: http://www.addictionresearchchair.ca/wp-content/up loads/Youth-Volatile-Solvent-Abuse.pdf.

11. Frey H. Dendritic Polymers: Universal Glue for Cells. Nature Materials. 2012;11:359-60.

12. Shepherd RT. Mechanism of Sudden Death Associated with Volatile Substance Abuse. Human Toxicology. 1989;8(4):287-91.

13. Marshall J. The Dangers Of Inhalants: Inform Yourself and Talk to Your Children. My Addiction: An Online Addiction and Recovery Resource. 2014 [cited 2016 Nov 6]. Available from: http://www.myaddiction.com/lifestyle/drugs/the-dan gers-of-inhalants-inform-yourself-and-talk-to-yourchildren

14. Ministry of Children affairs. The Children Act 2011. Government of the People's Republic of Bangladesh. 2011 [cited 2014 Octo 30]. Available from: http://www.msw.gov.bd/.

15. Nawaz S. Development Policies for Street Children in Bangladesh: A Special Emphasis on Education Program. 2011 [cited 2016 Nov 6]. Available from: https://lup.lub.lu.se/luur/download?func=download File\&recordOId=2164018\&fileOId=2164054 